\title{
Sistemas Primários de Transporte de Prótons Integram os mecanismos de Desintoxicação do Mesotrione em Plantas de MILHO ${ }^{1}$
}

\author{
Proton Transport Primary Systems Used as Mechanisms of Mesotrione Detoxification in Corn \\ Plants
}

\author{
OGLIARI, J. ${ }^{2}$, FREITAS, S.P. ${ }^{3}$, RAMOS, A.C. ${ }^{4}$, BRESSAN SMITH, R.E. ${ }^{5}$ e \\ FAÇANHA, A.R. ${ }^{6}$
}

\begin{abstract}
RESUMO - O mesotrione é um dos mais efetivos herbicidas desenvolvidos para o controle de uma ampla gama de plantas daninhas que infestam campos de milho (Zea mays). Todavia, as bases bioquimicas e moleculares da tolerância das plantas de milho a esse herbicida ainda não foram estabelecidas. Para compreender os mecanismos de desintoxicação do mesotrione em plantas de milho, foram analisadas as atividades dos principais sistemas primários de transporte de prótons (ions $\left.\mathrm{H}^{+}\right)$das membranas plasmática e vacuolar $\left(\mathrm{H}^{+}\right.$-ATPases do tipo $\mathrm{P}$ e $\mathrm{V}$ e $\mathrm{H}^{+}$-PPases) de células de diferentes tecidos de plantas tratadas após aplicação do herbicida em pós-emergência. Para isso, foram realizados procedimentos de fracionamento celular, de tecidos radiculares, foliares e do caule, por centrifugação diferencial e purificação de vesículas membranares em gradiente de densidade de sacarose. Os ensaios enzimáticos das atividades hidroliticas das três bombas de $\mathrm{H}^{+}$foram realizados aplicando-se um método colorimétrico para medir o fosfato liberado das hidrólises dos substratos: adenosina-5'trifosfato (ATP) e pirofosfato (PPi). Parâmetros fotossintéticos foram analisados como marcadores fisiológicos dos diferentes estádios da desintoxicação das plantas. Essa análise demonstrou que o tratamento com mesotrione promoveu uma redução na taxa fotossintética e na relação Fv/Fm no terceiro dia após aplicação (DAA), mas não afetou significativamente a fotossintese a partir do quinto DAA. Nos três tecidos analisados, raiz, folha e caule, aos 3 DAA, foi observado forte estimulo da atividade da $\mathrm{H}^{+}$-PPase vacuolar, a qual variou de cerca de 100 a 600\%. Essa forte ativação foi reduzida significativamente aos 7 DAA, mas permaneceu pelo menos duas vezes maior com relação ao controle. Por sua vez, as $\mathrm{H}^{+}$-ATPases das membranas plasmática e vacuolar foram bem menos moduladas pelo tratamento com o herbicida, apresentando estimulações e inibições que não variaram mais do que 20 a $60 \%$ das atividades obtidas em vesiculas de membranas oriundas de plantas não tratadas (controle). Os resultados demonstraram que o mesotrione promove uma ativação diferencial dos principais sistemas primários de transporte de $\mathrm{H}^{+}$, indicando que essas bombas iônicas são enzimas transportadoras essenciais aos mecanismos relacionados com o processo de desintoxicação das plantas de milho, possivelmente ao energizar a compartimentalização das moléculas do herbicida mesotrione no vacúolo ou a exceção celular através das membranas plasmáticas.
\end{abstract}

Palavras-chave: Zea mays, herbicida, fitotoxidez, $\mathrm{H}^{+}$-ATPase, V-ATPase, $\mathrm{H}^{+}$-PPase.

1 Recebido para publicação em 24.11.2008 e na forma revisada em 13.11.2009

2 Dr., em Fitotecnia, Universidade Estadual do Norte Fluminense Darcy Ribeiro - UENF, Campos dos Goytacazes-RJ, <juares@uenf.br>; ${ }^{3}$ Professor do Lab. de Fitotecnia - UENF, <silvério@uenf.br>; ${ }^{4}$ Professor do Lab. de Microbiologia Ambiental e Biotecnologia, Centro Universitário Vila Velha - LMAB/UVV, Vila Velha-ES, <alessandro.uvv@gmail.com>; ${ }^{5}$ Professor do Lab. de Fisiologia Vegetal (LMFV/CCTA) - UENF, <bressan@uenf.br>; ${ }^{6}$ Professor do Lab. de Biologia Celular e Tecidual (LBCT/CBB) UENF, <arnoldo@uenf.br>.

Planta Daninha, Viçosa-MG, v. 27, n. 4, p. 799-807, 2009 


\begin{abstract}
The herbicide Mesotrione herbicides are very effective in the control of a wide range of weeds that infest corn (Zea mays) fields. However, the biochemical and molecular bases of corn seedling tolerance to this herbicide have not been established so far. To understand the mechanisms of mesotrione detoxification in corn plants, the activities of the main primary proton $\left(H^{+}\right.$ion) transport systems of the vacuolar and plasma membranes $\left(H^{+}\right.$-ATPases $V$ - and P-types, and $H^{+}$-PPase) of the cells from different tissues were analyzed, after post-emergence herbicide application. Thus, cell fractionation procedures on root, leaf and mesocotyl tissues were performed using differential membrane vesicle centrifugation and purification in sucrose density gradient. Hydrolytic activities of the proton pumps were measured by using a colorimetric method for phosphate released through enzymatic hydrolysis of the substrates adenosine-5'-triphosphate (ATP) and pyrophosphate (PPi). Photosynthetic parameters were analyzed as physiological markers of the different stages of plant detoxification. Such analysis demonstrated that, three days after herbicide application (DAA), mesotrione induced a reduction in the photosynthetic rate and Fv/Fm ratio, but no significant effect could be found after the fifth DAA. These data suggest that the treatment with mesotrione promoted a spatial and temporal regulation of the $H^{+}$pump activities. In all the root, leaf and mesocotyl tisues analyzed, at three DAA, a strong stimulation of the vacuolar $H^{+}$-PPase activity was observed, varying from $100 \%$ to $600 \%$. This activation was significantly reduced at the seventh DAA, but remained at least twice higher than the controls. On the other hand, the vacuolar and plasma membranes $H^{+}$-ATPases were much less modulated by the herbicide treatment, exhibiting stimulations and inhibitions which did not change by more than 20 to $60 \%$ in relation to the activities found in membrane vesicles derived from untreated plants (controls). The results demonstrate that mesotrione can promote a differential activation of the main primary proton transport systems, suggesting that these ion-pumps are transporting enzymes essential for the detoxification-related processes in corn plants, likely by energizing compartmentalization of the herbicide molecules into the vacuoles or cellular excretion through the plasma membrane.
\end{abstract}

Keywords: Zea mays, Herbicide, Phytotoxicity, $\mathrm{H}^{+}$-ATPase, V-ATPase, $\mathrm{H}^{+}$-PPase.

\section{INTRODUÇÃO}

O mesotrione é um herbicida de ação sistêmica indicado para controle de plantas daninhas na cultura de milho (Zea mays), aplicado em pós-emergência (Sprague et al., 1999; Rodrigues \& Almeida, 2005). As plantas absorvem esse herbicida principalmente através das folhas e raizes via movimento apossimplástico (Mitchell et al., 2001). As espécies de plantas suscetíveis ao mesotrione apresentam sintomas de amarelecimento nas folhas aos três dias após a aplicação (DAA), com posterior branqueamento, que progridem para a necrose e morte da planta em até duas semanas. Os sintomas se desenvolvem mais rapidamente na presença de luz (Pallet et al., 1998; Wichert et al., 1999; Johnson \& Young, 2002)

O mesotrione causa em algumas variedades ou híbrido de milho sintomas de fitointoxicação, porém isso não resulta em perdas na produtividade de grãos (Furtado, 2004; Masiunas et al., 2004). O milho é tolerante ao mesotrione, provavelmente, devido à capacidade de desativação do princípio ativo e à translocação para compartimentos celulares
- vacúolo e meio extracelular (Mitchell et al., 2001; Johnson \& Young, 2002; O`Sullivan et al., 2002). A capacidade de realizar a desintoxicação de herbicida é desencadeada pelo aparato bioquímico celular (Kreuz et al., 1996). Portanto, a maioria das moléculas de herbicida são translocadas para o interior do citoplasma via transportadores de membrana (Hess, 1985; Briskin, 1994; Sterling, 1994; Riechers et al., 1998). A energização desse processo é dependente do gradiente eletroquímico gerado pelos transportadores primários de prótons, denominados bombas de prótons $\left(\mathrm{H}^{+}\right)$, que estão localizadas na membrana plasmática (Coleman et al., 1997; Hull \& Cobb, 1998). Quando as moléculas de herbicida estão no citoplasma de plantas tolerantes, elas são removidas para o vacúolo ou apoplasto através dos transportadores secundários, os quais são energizados pelas bombas de $\mathrm{H}^{+}$(Ros et al., 1990; Martinoia et al., 1993; Gaillard et al., 1994; Kreuz et al., 1996).

Em plantas tolerantes, a metabolização e a desintoxicação dos herbicidas são realizadas em quatro fases distintas (Kreuz et al., 1996; Li et al., 1997). Na fase I (ativação) ocorre a exposição ou introdução de grupos funcionais 
por meio de reações, que normalmente envolvem hidrólise, oxidação ou redução, tornando as moléculas de herbicida ativas para as enzimas atuarem nas fases seguintes (Kreuz et al., 1996; Coleman et al., 1997; Eerd et al., 2003). Na fase II (conjugação), o herbicida ativado é conjugado por meio de moléculas hidrofilicas endógenas (Lamoureux et al., 1991; Riechers et al., 1998), aminoácidos e proteínas (Kreuz et al., 1996; Coleman et al., 1997; Hatzios, 1997; Eerd et al., 2003). Na fase III (eliminação), o conjugado é translocado para o interior do vacúolo ou excretado para o apoplasto, através de transportadores ABC (ATP-binding cassette) e/ou secundários (antiporters e simporters), sendo energizados pelas bombas de prótons V-ATPase e $\mathrm{H}^{+}$-PPase (Martinoia et al., 1993; Hatzios, 1997; Eerd et al., 2003). Na fase IV (transformação), os conjugados que foram transportados são posteriormente hidrolisados ou degradados (Sandermann, 1992; Kreuz et al., 1996; Coleman et al., 1997; De Prado \& Franco, 2004).

Vários estudos relatam a atuação dos herbicidas no metabolismo das plantas, porém poucos trabalhos abordam a participação das bombas $\mathrm{H}^{+}$(plasmalema e tonoplasto) na translocação dos herbicidas para o interior da célula e a eliminação para o exterior do citoplasma. Dessa forma, é importante compreender como as diversas classes de herbicidas interagem com as bombas de $\mathrm{H}^{+}$em plantas tolerantes ou resistentes. Em plantas de milho, que são tolerantes ao herbicida mesotrione, não há informação sobre se esse produto químico interfere ou não na atividade hidrolítica das enzimas. Assim, é possivel que esses sistemas possam participar nos mecanismos de tolerância/desintoxicação do herbicida mesotrione nas plantas de milho. Este trabalho teve como objetivo verificar a desintoxicação do mesotrione em plantas de milho por meio da atividade hidrolitica das bombas de prótons $\left(\mathrm{H}^{+}\right)$ presentes nas membranas plasmática $\left(\mathrm{H}^{+}-\right.$ ATPase) e vacuolar (V-ATPase e $\mathrm{H}^{+}$-PPase), nos tecidos de folha, caule e raiz.

\section{MATERIAL E MÉTODOS}

$O$ experimento foi conduzido na Unidade de Apoio a Pesquisa (UAP) do Centro de Ciências e Tecnologias Agropecuárias (CCTA), no campus da Universidade Estadual do Norte
Fluminense Darcy Ribeiro (UENF), Campos dos Goytacazes-RJ, no período de setembro de 2005 a março de 2006. As plantas de milho (híbrido Braskalb 330) foram cultivadas em vasos de 4,5 litros com substrato areia e solo (2:1) a céu aberto. Foram semeadas quatro sementes de milho em cada vaso e aos oito dias após o plantio (DAP) foi realizado o desbaste, permanecendo apenas uma planta, que recebeu $350 \mathrm{~mL}$ de solução nutritiva de Clark (1975). As plantas foram irrigadas diariamente, mantendo-se o teor de umidade no vaso próximo à capacidade de campo. A dose do herbicida mesotrione utilizado no ensaio foi de $192 \mathrm{~g} \mathrm{ha}^{-1}$, que corresponde à dose máxima recomendada para o controle das plantas daninhas na cultura do milho (Rodrigues \& Almeida, 2005). A aplicação foi realizada aos $15 \mathrm{DAP}$, quando as plantas de milho estavam no estádio de quatro folhas. A aplicação nos tratamentos com herbicida foi realizada utilizando pulverizador costal, pressurizado a $\mathrm{CO}_{2}$, em pressão constante de $3,0 \mathrm{kgf} \mathrm{cm}^{-2}$ e equipado com um bico Teejet DG 8002 , o qual foi calibrado para aplicar o equivalente a $230 \mathrm{~L} \mathrm{ha}^{-1}$ de calda. A aplicação foi realizada às $7 \mathrm{~h}$ da manhã, com umidade relativa de $70 \%$ e velocidade do vento inferior a $7 \mathrm{~km} \mathrm{~h}^{-1}$.

$\mathrm{Na}$ avaliação das atividades hidroliticas das bombas de prótons foram utilizados tratamentos controle e mesotrione, constituídos por sete parcelas (vasos) aos três dias após a aplicação (DAA) e aos 7 DAA, com quatro repetições para cada tratamento. Nos tratamentos foram utilizados tecidos de raiz, caule e folhas. Os tecidos vegetais coletados foram armazenados no gelo e pesados, obtendo-se da raiz $18 \mathrm{~g}$, do caule $12 \mathrm{~g}$ e da folha $8 \mathrm{~g}$, para posterior extração das proteínas.

$\mathrm{O}$ isolamento da membrana plasmática e do tonoplasto foi realizado por meio de centrifugação diferencial, como descrito por Giannini \& Briskin (1987), com modificações (Façanha \& De Meis, 1998).

Os tecidos da raiz, caule e folhas, após pesagem, foram macerados, com auxilio de gral e pistilo em meio tamponado $\mathrm{pH} 8,0$ composto de $250 \mathrm{mM}$ de sacarose, $100 \mathrm{mM}$ de $\mathrm{KCl}, 15 \%$ de glicerol, $100 \mathrm{mM}$ de tris-base (hidroximetil aminometano), $05 \mathrm{mM}$ de EDTA (ácido etilenodiaminotetracético), $05 \mathrm{mM}$ de DTT (Ditiotreitol), $01 \mathrm{mM}$ de PMSF (fenilmetilsulfonil 
fluoreto), 0,8\% de PVP-40T (Polivinil poli pirrolidona) e $01 \mathrm{mM}$ de benzamidina. Posteriormente, o macerado foi filtrado por meio de quatro camadas de gaze e centrifugado a $3.000 \times g$ por 15 min a $4{ }^{\circ} \mathrm{C}$ (Centrifuga Himac CR21 marca Hitachi). O sobrenadante foi centrifugado novamente em ultracentrífuga (modelo CP $75 \beta$, HITACHI, Japan) a $30.000 \times 9$ por $10 \mathrm{~min}$ a $4{ }^{\circ} \mathrm{C}$. O precipitado, composto principalmente de mitocôndrias e peroxissomos, foi descartado e o sobrenadante novamente centrifugado na mesma centrifuga a $100.000 \times g$ por $30 \mathrm{~min}$ a $4{ }^{\circ} \mathrm{C}$. Após a centrifugação, o precipitado foi ressuspendido em homogeneizador, com solução-tampão de: $15 \%$ de glicerol, $70 \mathrm{mM}$ de Tris- $\mathrm{HCl}$ (pH 7,6), $05 \mathrm{mM}$ de EDTA, $01 \mathrm{mM}$ de DTT, $01 \mathrm{mM}$ de benzamidina e $01 \mathrm{mM}$ de PMSF.

A fração microssomal de todas as membranas foram ressuspendidas e pipetadas sobre um gradiente de concentração descontínuo de sacarose de $46 \%$ e $25 \%$, para a fração dos tecidos de raiz e de caule, e de $46 \%, 40 \%$ e $32 \%$ na folha com solução-tampão de $25 \mathrm{mM}$ de tris- $\mathrm{HCl}, 2 \mathrm{mM}$ de EDTA, $01 \mathrm{mM}$ de DTT, $1 \mathrm{mM}$ de PMSF e $1 \mathrm{mM}$ de benzamidina, como descrito por Serrano (1989), com modificações (Façanha \& De Meis, 1998). Esse gradiente foi submetido a uma centrifugação de $100.000 \times \mathrm{g}$ por $2 \mathrm{~h}$ a $4{ }^{\circ} \mathrm{C}$, com a formação de duas bandas contendo as vesículas de tonoplasto e plasmalema. As bandas foram coletadas e armazenadas a $-70{ }^{\circ} \mathrm{C}$, para posterior análise. $\mathrm{O}$ conteúdo de proteína das membranas plasmática e do tonoplasto foi determinado utilizando o método descrito por Bradford (1976).

As atividades das $\mathrm{H}^{+}$-ATPase e $\mathrm{H}^{+}$-PPase foram determinadas colorimetricamente, medindo-se a quantidade de fosfato inorgânico (Pi) liberado pela reação, como descrito por Fiske \& Subbarrow (1925), com modificações (Façanha \& De Meis, 1998). As concentrações finais dos reagentes no meio de reação para atividade ATPásica em vesículas de membrana plasmática foram as seguintes: $50 \mathrm{mM}$ de MOPS-KOH (ácido 3-(N-morfino) propano sulfônico) em pH 7,0 para fração vacuolar; $3 \mathrm{mM}$ de $\mathrm{MgSO}_{4} ; 100 \mathrm{mM}$ de $\mathrm{KCl} ; 1 \mathrm{mM}$ de ATP (ou 0,1 mM PPi); e $50 \mu$ g de proteína. Cada amostra foi colorida com solução de $0,5 \%$ de molibdato de amônio e $2 \%$ de ácido sulfúrico, acrescida a uma solução de $10 \%$ de ácido ascórbico na proporção de 10:1, sendo interrompida pela adição de ácido tricloroacético (TCA) numa concentração final de 5\%. Após coloridas, as amostras foram incubadas a $37^{\circ} \mathrm{C}$ por $10 \mathrm{~min}$ em banho-maria, realizando-se imediatamente a leitura da absorbância no comprimento de onda de $750 \mathrm{~nm}$, obtendo-se a densidade ótica. A atividade da $\mathrm{H}^{+}$-ATPase da membrana plasmática foi avaliada na presença e ausência do inibidor vanadato a $2 \mathrm{mM}$, enquanto a $\mathrm{H}^{+}$-PPase das vesículas de membrana do tonoplasto foi avaliada na presença e ausência de potássio. A atividade hidrolitica da $\mathrm{H}^{+}$-ATPase, V-ATPase e $\mathrm{H}^{+}$-PPase foi determinada pela subtração dos valores do $\mathrm{Pi}$, na ausência e presença de vanadato e potássio. Os valores de $\mathrm{Pi}$ obtidos das atividades hidroliticas das três bombas de prótons foram transformados em porcentagem de aumento ou inibição do tratamento mesotrione, em relação ao controle, para as quatro repetições.

Para as medições da taxa fotossintética e da eficiência fotoquímica, com base na fluorescência da clorofila $a$, nas folhas de milho, as plantas foram submetidas às mesmas condições do experimento da atividade hidrolítica. No estudo da taxa fotossintética e fluorescência da clorofila $a$, foram utilizadas 5 e 20 plantas por tratamento, respectivamente. A medição foi realizada na quarta folha, na posição central do limbo foliar. A fotossíntese foi mensurada em um aparelho com analisador de gás no infravermelho LI-6200 (Licor., NE, USA), com um conjunto de lâmpadas (LED) acoplado à superfície da câmara do IRGA, possibilitando a obtenção de um fluxo de fótons fotossintéticos de $500 \mu \mathrm{mol} \mathrm{m} \mathrm{m}^{-2} \mathrm{~s}^{-1}$ sem aquecimento do tecido foliar. Todas as medições foram efetuadas entre 7 e 10 horas da manhã. As determinações relativas da emissão de fluorescência da clorofila $a$ foram efetuadas em temperatura ambiente, por meio de um fluorômetro de luz não modulada, modelo PEA (Plant Efficiency Analyser, Hansatech, King's Lynn, Norkfolk, UK), onde foram registrados os valores das fluorescências inicial (Fo) e máxima $(\mathrm{Fm})$, a capacidade fotoquímica do fotossistema II ou rendimento quântica máximo $(\mathrm{Fv} / \mathrm{Fm}=$ fluorescência variável/fluorescência máxima). 


\section{RESULTADOS E DISCUSSÃO}

Os sintomas visuais de fitointoxicação nas plantas de milho tratadas com mesotrione iniciaram-se principalmente na terceira e na quarta folha a partir dos 3 DAA. Esses sintomas foram reduzindo progressivamente a partir dos 7 DAA, e aos 12 DAA não se observou nenhuma evidência visual de fitointoxicação. As folhas que surgiram após a aplicação do herbicida não apresentaram sintomas. Os dados obtidos podem ser indicativos de que as bombas de $\mathrm{H}^{+}$participam nas vias de desintoxicação do mesotrione em plantas de milho.

Ressalta-se que a fotossintese é importante na estratégia para a análise de plantas tratadas com herbicida. Observou-se que o herbicida mesotrione reduziu a taxa fotossintética nas plantas de milho em $78 \%$ no primeiro dia, $66 \%$ no segundo dia e $75 \%$ no terceiro DAA, em relação ao controle. Entretanto, aos 5 e 7 DAA, a taxa fotossintética nos tratamentos não apresentou diferenças significativas (Figura 1A). Na medição da fluorescência da clorofila $a$ das folhas, constatou-se que o mesotrione diminuiu o rendimento quântica máximo $\left(\mathrm{F}_{\mathrm{v}} / \mathrm{F}_{\mathrm{m}}\right)$, em comparação ao tratamento controle (Figura 1B). Esta razão entre as $F_{v} / F_{m}$ expressa a eficiência relativa de captura da energia de excitação pelos centros de reação abertos do fotossistema II (FS II) (Krause \& Weis, 1991). Segundo Haehnel et al. (1982), essa variável representa a eficiência quântica do transporte de elétrons por meio do FS II. A relação $F_{v} / F_{m}$ diminuiu em plantas tratadas com mesotrione, atingindo valores na ordem de $52 \%, 26 \%$ e $17 \%$ no primeiro, segundo e terceiro DAA, respectivamente; aos 5 DAA não ocorreu diferença significativa entre os tratamentos. Constatouse então que as folhas foram os tecidos mais afetados pelo tratamento químico, sendo evidentes os sintomas de fitointoxicação no terceiro DAA. Entretanto, aos 12 DAA as plantas estavam totalmente recuperadas, não apresentando diferenças significativas nas variáveis fotossintéticas, nos sintomas visuais de fitointoxicação e nas atividades enzimáticas das bombas de prótons.

A atividade hidrolitica da bomba $\mathrm{H}^{+}$-PPase em tecidos de folhas no tratamento com mesotrione apresentou ativação em torno de
$600 \%$ aos 3 DAA (Figura 2A), sendo reduzida à metade aos 7 DAA, em relação ao controle. A atividade da V-ATPase e $\mathrm{H}^{+}$-ATPase aos 3 DAA não apresentou alteração significativa, porém aos 7 DAA essas bombas foram estimuladas em $57 \%$ e $18 \%$, respectivamente, em relação ao controle (Figura 2B e C).

Em tecidos de caule tratados com mesotrione a atividade da $\mathrm{H}^{+}$-PPase foi estimulada em 191\% aos 3 e 144\% aos 7 DAA, em relação ao controle (Figura 3A). Já a atividade da V-ATPase e $\mathrm{H}^{+}$-ATPase sofreu uma modulação diferencial (Figura 3B e C), com estimulação de $21 \%$ e $64 \%$ aos 3 DAA e inibição de $28 \%$ e $40 \%$ aos 7 DAA, respectivamente, em relação ao controle.

A ativação da $\mathrm{H}^{+}$-PPase pode estar relacionada à maior quantidade de PPi (pirofosfato inorgânico) em relação ao ATP, visto que a produção de ATP foi prejudicada pela diminuição da fotossíntese decorrente da fitointoxicação

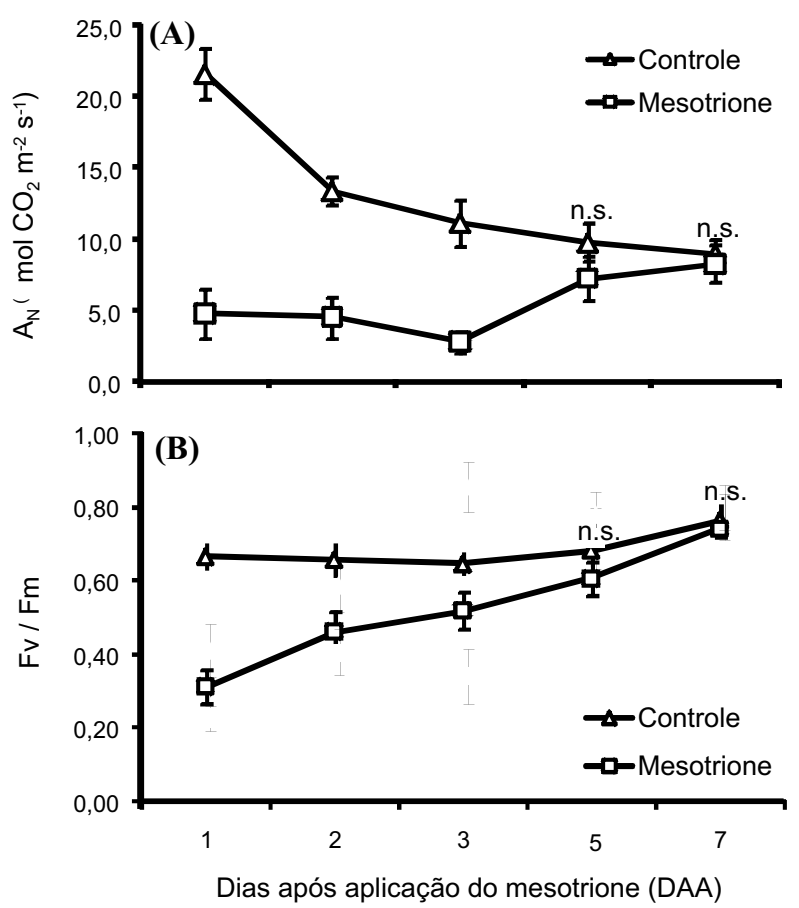

Os dados são expressos em médias \pm desvio-padrão obtidos de dois experimentos independentes. n.s. não estatisticamente diferente pelo teste t-Student a $5 \%$ de significância.

Figura 1 - Taxa fotossintética (A) e relação Fv/Fm (B) em plantas de milho controle e tratadas com mesotrione (192 $\left.\mathrm{g} \mathrm{ha}^{-1}\right)$ em diferentes dias após a aplicação (DAA) (1, $2,3,5$ e 7 dias).

Planta Daninha, Viçosa-MG, v. 27, n. 4, p. 799-807, 2009 

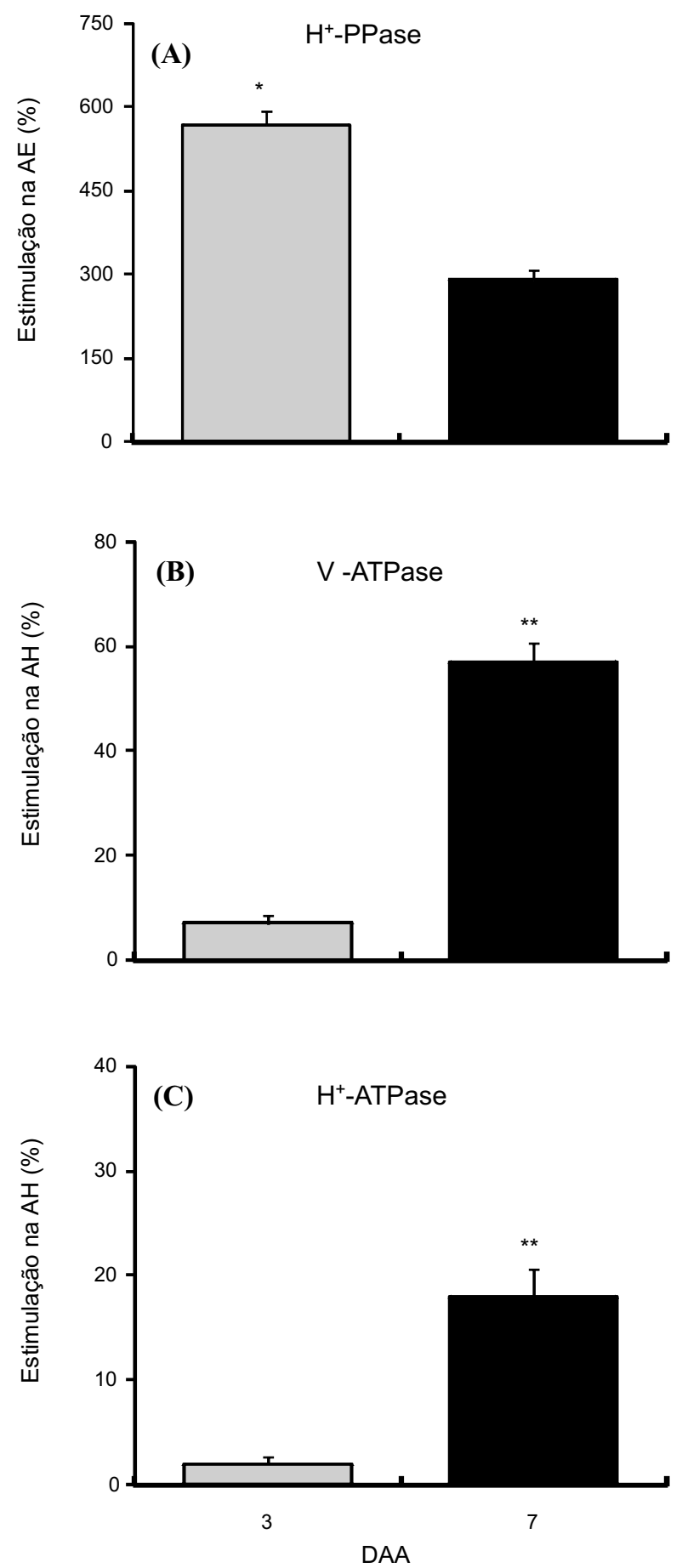

Os dados são expressos em médias \pm desvio-padrão obtidos de três experimentos independentes; médias estatisticamente diferentes pelo teste t-Student a $1 \%(* *)$ e $5 \%(*)$ de probabilidade.

Figura 2 - Porcentagem de estimulação da atividade hidrolítica da $\mathrm{H}^{+}$-PPase (A), V-ATPase (B) e $\mathrm{H}^{+}$-ATPase (C) em tecidos de folha, após o tratamento com $192 \mathrm{~g} \mathrm{ha}^{-1}$ do herbicida mesotrione aos três e sete dias após a aplicação (DAA). Os resultados são baseados no controle não tratado.
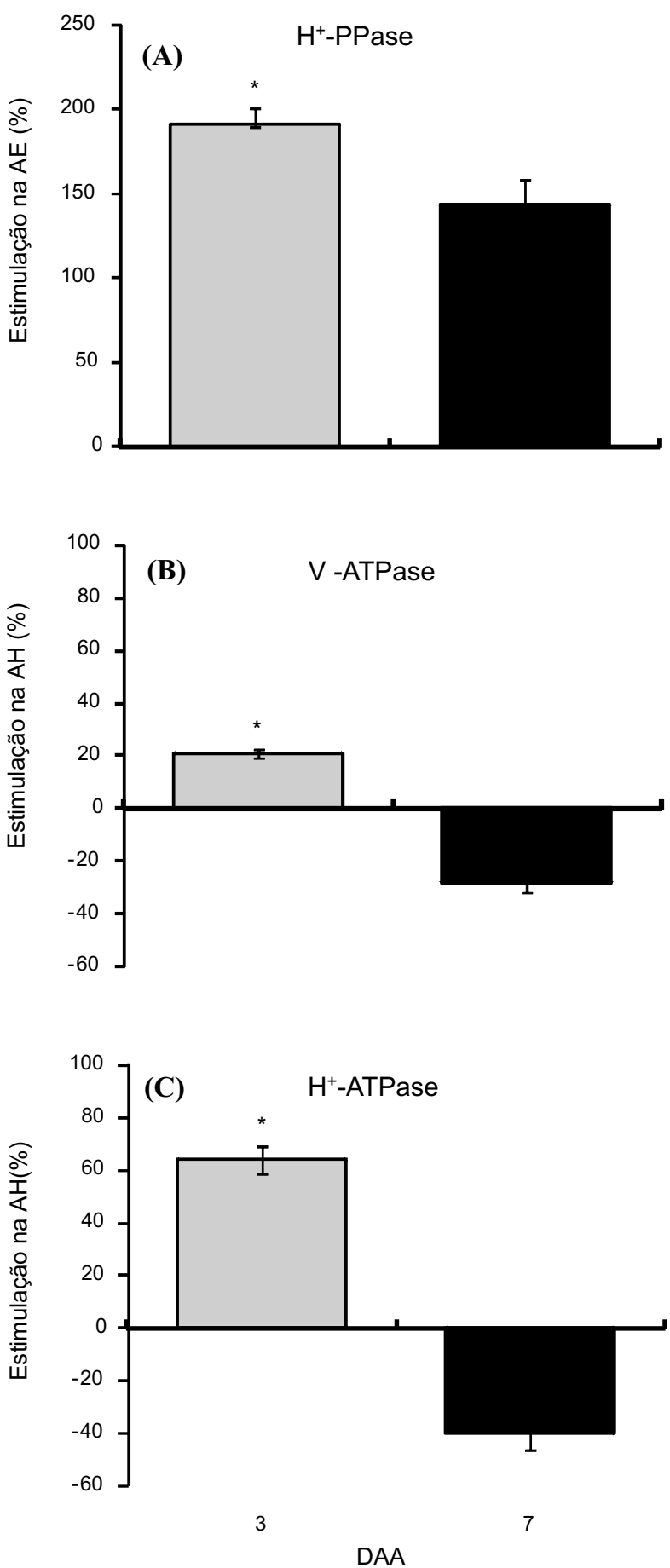

Os resultados são baseados no controle não tratado. Os dados são expressos em médias \pm desvio-padrão obtidos de três experimentos independentes. n.s - médias não estatisticamente diferentes pelo teste t-Student a $1 \%(* *)$ e $5 \%(*)$ de probabilidade.

Figura 3 - Porcentagem de estimulação (+) ou inibição (-) da atividade hidrolítica da $\mathrm{H}^{+}$-PPase (A), V-ATPase (B) e $\mathrm{H}^{+}-$ ATPase (C) em tecidos de caule, após o tratamento com $192 \mathrm{~g} \mathrm{ha}^{-1}$ do herbicida mesotrione aos três e sete dias após a aplicação (DAA) 
desse tecido. Nos vegetais, o PPi é considerado um substrato alternativo ao ATP, podendo ativar o metabolismo energético em condições de estresse, quando ocorre a redução dos niveis de ATP no citoplasma (Stitt, 1998; Façanha \& De Meis, 1998). O ATP na planta é produzido por meio da glicólise, da fosforilação oxidativa e, principalmente, da fotossintese (Nakanishi \& Maeshima, 1998).

Segundo Palma et al. (2000), o PPi fornece energia alternativa à $\mathrm{H}^{+}$-PPase no transporte de prótons do citossol para o vacúolo, atuando como importante fornecedor de energia para os transportadores secundários em plantas submetidas a estresse, nos quais a produção de ATP pode ser prejudicada. Essa observação pode ser confirmada com a baixa atividade hidrolitica da $\mathrm{H}^{+}$-ATPase e V-ATPase, que utilizam como substrato o ATP. Portanto, a elevada ativação na $\mathrm{H}^{+}$-PPase nos tecidos estudados pode estar relacionada com a redução de ATP nas plantas de milho submetidas ao tratamento com mesotrione.

Nos tecidos de raízes tratadas com herbicidas, a atividade da $\mathrm{H}^{+}$-PPase foi estimulada em $114 \%$ aos 3 e 123\% aos 7 DAA, em relação ao controle (Figura 4A). Já as bombas V-ATPase e $\mathrm{H}^{+}$-ATPase não apresentaram atividades aos 3, e aos 7 DAA apenas a V-ATPase foi estimulada em $52 \%$, em relação ao controle (Figura 4B e C). Serrano (1989) mostrou que a V-ATPase pode ser regulada por muitos fatores fisiológicos, entre os quais hormônios, luz, fitotoxinas e também por herbicidas. Apesar de o mesotrione induzir muito menos as $\mathrm{H}^{+}-$ ATPases, em comparação com seu marcante efeito sobre a $\mathrm{H}^{+}$-PPase, não se deve subestimar o possivel papel das ATPases da membrana plasmática, as quais poderiam energizar a extrusão do herbicida para fora das células do milho.

Em conjunto, os resultados obtidos fornecem fortes evidências de uma participação importante das bombas $\mathrm{H}^{+}$nos mecanismos de desintoxicação do herbicida mesotrione em plantas de milho. O tratamento com o mesotrione promoveu elevada estimulação da atividade hidrolitica da $\mathrm{H}^{+}$-PPase, principalmente nos estádios iniciais do tratamento, em todos os tecidos analisados nos diferentes estádios do desenvolvimento das plantas, indicando ser esta a principal bomba de prótons
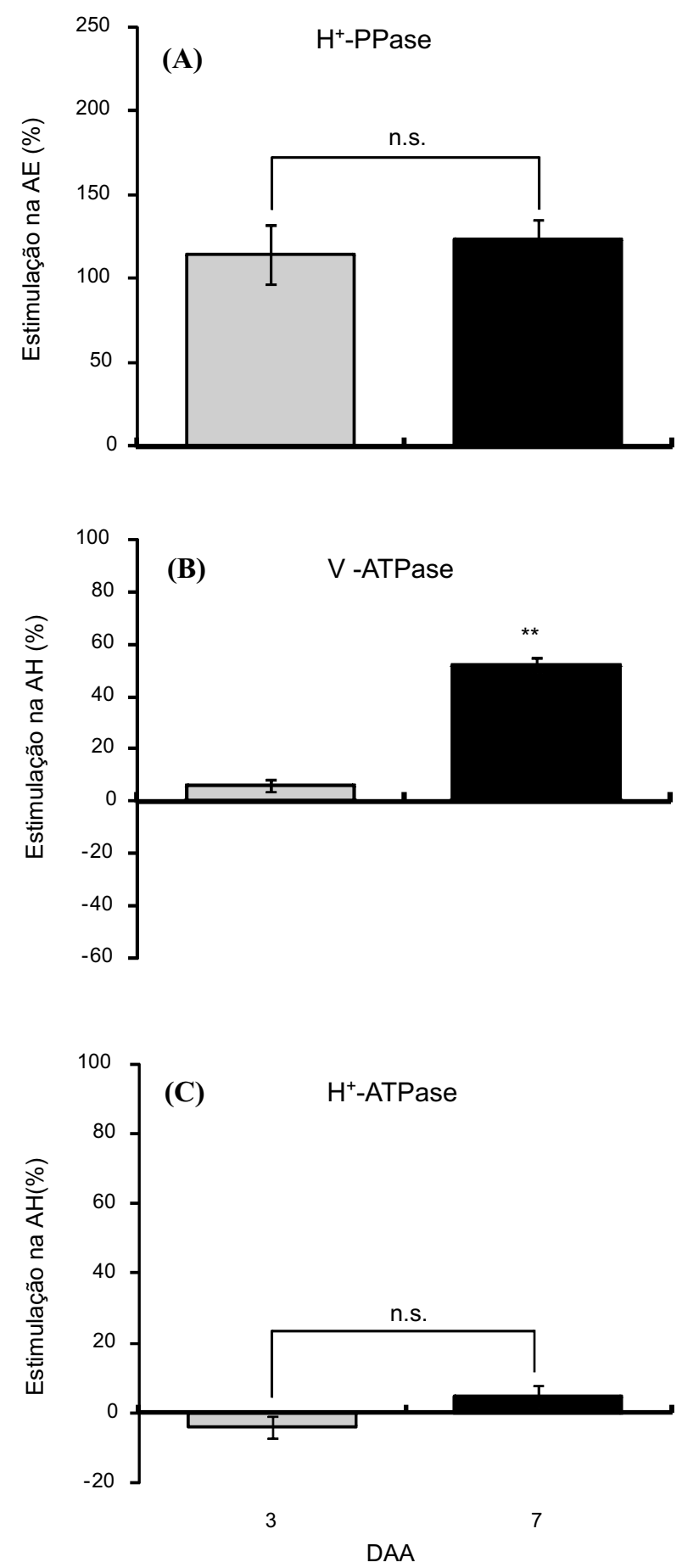

Os resultados são baseados no controle não tratado. Os dados são expressos em médias \pm desvio-padrão obtidos de três experimentos independentes. n.s - médias não estatisticamente diferentes pelo teste t-Student a $1 \%\left({ }^{*}\right)$ e $5 \%(*)$ de probabilidade.

Figura 4 - Porcentagem de estimulação (+) ou inibição (-) da atividade hidrolítica da $\mathrm{H}^{+}$-PPase (A), V-ATPase (B) e $\mathrm{H}^{+}$ATPase (C) em tecidos de raízes, após o tratamento com $192 \mathrm{~g} \mathrm{ha}^{-1}$ do herbicida mesotrione aos três e sete dias após a aplicação (DAA).

Planta Daninha, Viçosa-MG, v. 27, n. 4, p. 799-807, 2009 
envolvida nas respostas de tolerância do milho à aplicação desse herbicida. Estudos mais aprofundados são necessários para revelar o papel das $\mathrm{H}^{+}$-PPases na ativação do gradiente de $\mathrm{H}^{+}$transmembrana e, consequentemente, dos transportadores secundários responsáveis pela compartimentalização do mesotrione no vacúolo, revelando assim as bases bioquímicas e moleculares da desintoxicação do mesotrione em plantas de milho.

\section{AGRADECIMENTO}

Ao CNPq, pela concessão da bolsa e pelo apoio financeiro.

\section{LITERATURA CITADA}

BRADFORD, M. M. A rapid and sensitive method for the quantitation of microgram quantities of protein utilizing the principle of protein-dye binding. Anal. Biochem., v. 72, n. 3, p. 248-254, 1976.

BRISKIN, D. P. Membrane and transport systems in plants: an overview. Weed Sci., v. 42, n. 2, p. 255-262, 1994.

CLARK, R. B. Characterization of phosphatase of intact maize roots. J. Agric. Food Chem., v. 23, n. 3, p. 458-460, 1975.

COLEMAN, J. O.; BLAKE-KALFF, M. M.; DAVIES, T. E. Detoxification of xenobiotics by plants: chemical modification and vacuolar compartmentation. Reviews: Trends Plant Sci. v. 2, n. 4, p. 144-151, 1997.

DE PRADO, R. A.; FRANCO, A. R. Cross-resistance and herbicide metabolism in grass weeds in Europe: biochemical and physiological aspects. Weed Sci., v. 52, n. 2, p. 441-447, 2004.

EERD, L. L. et al. Pesticide metabolism in plant and microorganisms. Weed Sci., v. 51, n. 3, p. 472-495, 2003.

FAÇANHA, A. R.; DE MEIS, L. Reversibility of $\mathrm{H}^{+}$-ATPase and $\mathrm{H}^{+}$-Pyrophosphatase in tonoplast vesicles from maize coleoptiles and seeds. Plant Physiol., v. 116, n. 1, p. 1487, 1998.

FISKE, C. F.; SUBBAROW, Y. The colorometric determination of phosphorus. J. Biol. Chem., v. 66, n. 5, p. 375,1925 .

FURTADO, D. A. S. Seletividade e eficácia agronômica do herbicida mesotrione na cultura do milho. 2004. $68 \mathrm{f}$. Dissertação (Metrado em FItotecnia) - Universidade Federal de Lavras, Lavras, 2004.
GAILLARD, C. et al. A. herbicide antidote (safener) induces the activity of both the herbicide detoxifying enzyme and of a vacuolar transporter for the detoxified herbicide. FEBS Letts, v. 352 , n. 2 , p. $219-21,1994$

GIANNINI, J. L.; BRISKIN, D. P. Proton transport in plasma membrane and tonoplast vesicles from red beet (Beta vulgaris L.) storage tissue. Plant Physiol., v. 84, n. 4, p. 613-618, 1987.

HATZIOS, K. K. Regulation of enzymatic systems detoxifying xenobiotics in plants: a brief overview and directions for future research. In: HATZIOS, K.K. (Eds.) Regulation of enzymatic systems detoxifying xenobiotics in plants. Dordrecht: Kluwer Academic Publishers, 1997. p. $1-5$.

HAEHNEL, W. et al. Picosecond flurescence kinetics and transfer in chloroplast and algae. Biochem. Biophys. Acta, v. 680, n. 1, p. $161-173,1982$.

HESS, F. D. Herbicide absorption and translocation and their relationship to plant tolerances and susceptibility. In: DUKE, S. O. (Ed.) Weed physiology. Boca Raton: CRC Press, 1985 p. 191-214. v. 2.

HULL, M. R.; COBB, A. H. An investigation of herbicide interaction with the $\mathrm{H}^{+}$-ATPase activity of plant plasma membranes. Pest. Sci., v. 53, n. 1, p. 155-164, 1998.

JOHNSON, C. B.; YOUNG, B. G. Influence of temperature and relative humidity on the foliar activity of mesotrione. Weed Sci., v. 50, n. 3, p. 157-161, 2002.

KRAUSE, G. H.; WEISS, E. Chlorophyll fluorescence and photosynthesis. Ann. Rev. Plant Physiol., v. 42, n. 1, p. 313-359, 1991.

KREUZ, K.; TOMMASINI, R.; MARTINOIA, E. Old enzymes for a new job: herbicide detoxification in plants Plant Physiol., v. 111, n. 5, p. 349-53, 1996.

LAMOUREUX, G. L.; SHIMABUKURO, R. H. A.; FREAR, D. S. Glutathione and glucoside conjugation in herbicide selectivity. In: CASELY, J. C.; CUSSANS, G.W.; ATKIN, R.K. (Eds.). Herbicide resistance in weeds and crops. Oxford: Butterworth-Heinemann, 1991. p. 227-261

LI, Z-S. et al. Vacuolar uptake of the phytoalexin medicarpin by the glutathione conjugate pump. Phytochemistry, v. 45, n. 3, p. 689-93, 1997.

MASIUNAS, J. et al. Sweet corn cultivar tolerance to mesotrione. Weed Sci. Soc. Am. Meeting Abstr., v. 44, p. $58,2004$.

MAESHIMA, M. Vacuolar $\mathrm{H}^{+}$-pyrophosphatase. Biochim. Biophys. Acta, v. 1465, n. 1, p. 37-51, 2000. 
MARTINOIA, E. et al. An ATP-dependent glutathione $S$-conjugate "export" pump in the vacuolar membrane of plants. Nature, v. 364, p. 247-49, 1993.

MITCHELL, G. et al. Mesotrione: a new selective herbicide for use in maize. Pest Manag. Sci., v. 57, n. 4, p. 120-128, 2001.

NAKANISHI, Y.; MAESHIMA, M. Molecular cloning of vacuolar $\mathrm{H}^{+}$-Pyrophosphatase and its developmental expression in growing hypocotyl of mung bean. Plant Physiol., v. 116, n. 1, p. 589-597, 1998.

O'SULLIVAN, J.; ZANDSTRA, J.; SIKKEMA, P. Sweet corn (Zea mays) cultivar sensitivity to mesotrione. Weed Technol., v. 16, n. 2, p. 421-425, 2002.

PALLET, K. E. et al. The mode of action of isoxaflutole. I. Physiological effects, metabolism, and selectivity. Pestic.

Biochem. Physiol., v. 62, n. 2, p. 113-124, 1998.

PALMA, D. A.; BLUMWALD, E.; PLAXTON, W. C. Upregulation of vacuolar $\mathrm{H}^{+}$- translocating pyrophosphatase by phosphate starvation of Brassica napus (rapeseed) suspension cell cultures. FEBS Letts, v. 486, p. 155-158, 2000.

RIECHERS, D. E. et al. Chromosomal location and expression of a herbicide safener-regulated glutathione S-transferase gene in Triticum aestivum and linkage relations in Hordeum vulgare. Genoma, v. 41, n. 4, p. 368-372, 1998.

RODRIGUES, B. N.; ALMEIDA, F. S. Guia de herbicidas. 5.ed. Londrina: IAPAR, 2005. p. 696.
ROS, R. et al. Effects of the herbicide MCPA, and the heavy metals, cadmium and nickel on the lipid composition, $\mathrm{Mg}^{2+-}$ ATPase activity and fluidity of plasma membranes from rice, Oryza sativa shoots. J. Exper. Bot., v. 41, n. 2, p. 457-462, 1990.

SANDERMANN, H. Plant metabolism of xenobiotics. Trends Biochem. Sci., v. 17, n. 2, p. 82-84, 1992.

SCHUMARCHER, K. Endomembrane proton pumps connecting membrane abd vesicle transport. Cell Biol., v. 9, n. 6, p. 595-600, 2006.

SERRANO, R. Structure and function of plasma membrane ATPase. Ann. Rev. Plant Physiol., v. 40, n. 1, p. 61-94, 1989.

SPRAGUE, C. L.; MAXWELL, D. J.; WAX, L. M. Compatisons of ZN. 1296 and RPA 201772 for weed control in corn. North Central Weed Sci. Soc., v. 56, n. 4, p. 223-224, 1999.

STERLING, T. M. Mechanisms of herbicide absorption across plant membranes and accumulation in plant cells. Weed Sci., v. 42, n. 2, p. 263-76, 1994.

STITT, M. Pyrophosphate as an energy donor in the cytosol of plant cells: an enigmatic alternative to ATP. Bot. Acta, v. 111, n. 3, p. 167-175, 1998.

WICHERT, R. A.; BARDETT, D. W.; TOWNSON, J. K. Mode of action, absorption, translocation and metabolism of mesotrione in weeds and corn. Proc. North Central Weed Sci. Soc., v. 54, n. 1, p. 94-95, 1999. 